\title{
The Normative Basis of Global Governance
}

\author{
Shaun Breslin ${ }^{1}$
}

Received: 18 December 2019 / Accepted: 20 December 2019 / Published online: 25 January 2020 (c) The Author(s) 2020

\begin{abstract}
How, if at all, are rising powers challenging the existing normative basis of global governance orders? This introduction establishes the overarching framework for the papers in this special issue, and outlines the questions that they collectively aim to answer.
\end{abstract}

Keywords Global governance $\cdot$ Global norms $\cdot$ Rising powers

In many ways, it would be surprising if the existing structures of global governance were not being challenged. The global financial crisis and ongoing turmoil and conflict in the Middle East and North Africa would be enough on their own to suggest that the status quo ante has not been particularly successful in ensuring the economic stability and security that one might reasonably expect it to provide. But there is more; there are other signs of governance deficits in other issue areas, too. The case of health governance and the early failure to respond effectively to the Ebola crisis covered in this collection by Lisk and Šehović is a good case in point. Moreover, President Trump's apparent lack of interest in providing the sort of global public goods that the USA has traditionally supplied, taking some of leadership roles that it has previously taken, and maintaining its previous commitment to some multilateral obligations, has only served to increase the sense that the current order is under threat.

If there is something we can identify as a liberal global order, and existing global governance structures form part of it, then in all of these cases, the challenge to this order has come from within rather from without. It is the failings of the governing systems themselves that has led to questions over their efficacy, and the strongest power (not external challengers) in that order that has decided to at least partially back away from its historical position. In addition, as Scholte notes in his contribution, there has been considerable dissatisfaction with the nature of the order and some of the principles that are meant to underpin it from within Western liberal

Shaun Breslin

Shaun.Breslin@warwick.ac.uk

1 Department of Politics and International Studies, University of Warwick, Coventry, UK 
democracies that are typically thought of as the major architects and beneficiaries of the system itself.

So it is not a simple case of the existing global order being challenged by a group of rising powers. The challenge is much more widespread. Nevertheless, it is right to add to what we might call "internal" challenges the consequences of ongoing power shifts and the increased confidence of rising powers to call for change to what Deciancio and Tussie refer to in their paper as "Western norms of order". At the heart of this dissatisfaction is the idea that there are structural biases in existing structures that favour some over others. These are not always obvious and evident. Mügge, for example, shows how even the statistics that we use to collect, report and evaluate economic performances and interactions contain in-built structural biases. More generally, however, there is a feeling that the norms that buttress global structures are not as universal as they claim to be, but rather represent the experiences and interests of a rather narrow set of countries that once had the power to put in place most of the structures that still shape the way the world works today. They are neither representative nor fair; and as already noted, not always effective either.

With this overarching context in mind, the contributors to this special issue were asked to focus on a number of key questions. These collectively get to the core of whether there really is a challenge to the normative basis of global governance, or whether it is more a case of trying to redistribute power and resources within the broadly defined status quo order. It was not the intention for all of the papers to deal with all of the questions. Instead, they provided a framework for the collection as a whole to address. The first question entails immediately unpacking this starting point and ask if there is a single set of ordering principles, ideas and ideals at all, or whether instead we can identify different normative orders in different issue areas. Following on from this, a second question is whether discontent represents an across-the-board type dissatisfaction with ordering principles, or whether there is more acceptance of the way things are done in some functional areas than in others. For example, in their contributions, Kahler, Jones and Menegazzi all question to various degrees the extent to which Chinese economic initiatives really represent a fundamental challenge to dominant modus operandi or if they are instead doing what has been done before in slightly different ways. These assessments are built on an understanding that while there might not be unconditional support for all preexisting principles, China and other developing economies have done quite well from the way that goods and finances have crossed borders in the post-Cold War era. Rather than seeking to change the norms and principles that drove globalization, it is the retreat from it-anti-globalization and economic nationalism-that provides the bigger challenge. So the suggestion here is that there might well be a greater appetite for supporting the existing nature of the economic order than in other areas; for example, when compared to the principles guiding humanitarian intervention. Or perhaps there is a desire to seek for reform rather than fundamental change in some areas, but a real and deep desire to fundamentally overturn basic starting points and principles in other areas.

Another resulting suggestion is that the China challenge to the global economic order might have been somewhat over-exaggerated. And a third question is whether the sort of public goods that these rising powers are increasingly seeking 
to provide - at the very least, in their own regional backyards - really represent an existential alternative to the pre-existing normative status quo, or do they rather represent a tool that states use to compete for dominance within the broadly defined existing governance parameters? Alternatively (or maybe simultaneously) do they fill gaps in existing structures that have not been adequately provided by current multilateral agencies at the global level? In short, when are we talking about change within the existing orders, and when is (if at all) an attempt to change the essential natures of those orders? The resulting fourth question is if we can identify reformist agendas rather than revisionist ones, how can current governance structures cope with and incorporate normative challenges and diversity without diluting the original ordering principles?

Fifth, if there is at least some challenge in some issue areas, where is that challenge coming from? The rising powers either individually, collectively or in different types of groupings are typically identified as the most likely source of new thinking and new preferences. And one of those rising powers seems to get more attention than others. This special issue arises from a workshop funded by and held at Fudan Institute for Advanced Studies in Social Sciences in Shanghai. A group of eminent Chinese scholars were invited to give their insights and to discuss the papers with the presenters, and their comments (along with those of anonymous reviewers) played an important role in shaping the final papers published in this collection. It is perhaps not surprising, then, that China looms large in the analysis in a number of the contributions. China looms large outside the pages of this journal, too, and is widely seen as being the major potential source of both a challenge to the status quo and also of new ideas and preferences.

This is entirely understandable. However, we were keen to ensure that this did not just become a China-centric analysis but instead looked more holistically at sources of discontent and potential alternatives. Collectively, the contributors to this book identify a range of countries where there is a desire to push for change that very much span the globe heading east (and south) from Russia and Turkey across Asia to Latin America. As such a sixth resulting question is whether there is anything that binds these different sources of dissatisfaction together beyond their original scope of dissatisfaction. Are there common positions that can bind different countries together in a single bloc, or once they agree on what they oppose, do they then fragment around different agendas? And what different mechanisms can be deployed (with what success) to gain buy-in and support from others? In short, as perhaps most clearly articulated by Lisk and Šehović in their introduction, how can rising powers best ensure not just that their preferences are heard, but that governance actually delivers what it is mean to provide?

Not surprisingly, there is typically an emphasis on what state elites want and think and how they go about trying to attain their goals. But whether we are talking about the nature of the status quo, where challenges to it are coming from, and what alternative future orders might look like, there is much more to it than just states. As such, the seventh question is what role can, do and/or should non-state actors play? For example, the entire point of Scholte's analysis is to look beyond statist approaches and solutions and to search for a new form of democratic global governance. As Cabellero-Anthony and others argue in this collection, the search 
for effective forms of governance entails bringing in a wide range of stakeholders. The extent of that range of actors varies from place to place and across issue areas, where one obvious task is to try and map who matters and why in different settings and functional arenas. In a very different way, Jones points to Chinaderived changes to governance norms in a number of areas emerging not from the intentional and deliberate action and desire of the Chinese state, but as accidental and at times dysfunctional consequences of decisions made by an assortment of Chinese economic actors.

Following on from this, the eighth and final main question is: what are the sites of governance contestation? A key collective theme in the contributions is the importance of thinking of different sites of authority where governance is both needed and provided. Arguably the most significant of these is the regional level, and this is reflected by the analysis in a number of the contributions. It is in the regional backyard, so the argument goes, that rising powers might be most able to promote their preferences and gain some acceptance of them; particularly if they are posed as being very different from the previously imposed preferences of the USA or "the West", and those western preferences are widely treated with some suspicion. But the region is not just important in its own right. It can also provide a testing ground for leadership ambitions that might subsequently be scaled up to the global level, and/or provide a regional support base for the wide promotion of these preferences to extra regional audiences.

The individual papers speak for themselves and have their own conclusions. Add them together and we get a picture of considerable unease with both the effectiveness of more established ways of providing global governance, and also the normative basis of many functional arrangements. What is much less clear is how this dissatisfaction can be converted into agendas for change that gain followership from others that are also dissatisfied; let alone how this dissatisfaction can be accommodated by those who are resistant to change. It is also a rather patchy picture with different constellations of opinions, interests and power in different issue areas, and in different regional settings. Rather than a single allencompassing holistic questioning of the normative basis of global governance per se, there is a general tendency for a more fragmented and indeed even inconsistent position: inconsistent in terms of the acceptance and commitment to the status quo in different issue areas.

Despite not wanting to make this all about China, it is nevertheless appropriate to finish this introduction by referring back to the Chinese case one more time. China's leaders have not been shy in enunciating their discontent with what is depicted as Western originated global normative orders. In recent years they have also been happy to promote China as a leader in pushing forward global governance reform, too. However, at the same time, there have been multiple statements of not just China's commitment to the international order, but that China is a key defender of it. If this sounds like a contradictory set of positions, the reason that it is not can be found in identifying the order and the ordering principles that China's leaders are committed to defending. This is not a commitment to a liberal global order or a US-led one. It is a commitment to what is seen as a prior and pre-existing order that has been constructed on the principle of the primacy of sovereignty. It is a sovereignty-based order that is argued to have been 
the founding principle of the United Nations system, and can be traced back to (at least) the Peace of Westphalia in 1648.

Crucially, this order is the one where no country should impose itself and its preferences over those of other sovereign entities. Countries might share a commitment to the same essential values - for example, the importance of human rights-but it is up to each country to define for itself exactly how that common value is understood, defined, prioritized and practiced based on its own experiences and conditions. The result should be a global order that does not privilege one interpretation or understanding over others, but instead not only allows for diversity, but encourages and facilitates it. The logical conclusion is a state of normative anarchy, with anarchy used here in the traditional international relations sense, namely the lack of any form of enforcing authority above the state. This could suggest a roll back from the global level as the key site of governance towards the nation state as the highest form of authority in the global order. Or if not anarchy, then perhaps a system where the only way to find commonly shared and agreed elements of norms is to make them so basic and thin that they are difficult to build anything substantive upon: certainly, thin compared to the much thicker individual interpretations of how each norm should be defined and operationalized in practice. But without this thin or shallow basis, it is hard to see how the status quo ante can generate the sort of support from the currently disaffected to ensure that they continue to provide governance forms that are both effective and also considered to be legitimate in large parts of the world. At the very least, it is probably fair to say that the process of challenge and contestation of the normative basis of governance at all levels (and not just the global one) is not likely to be a short-lived and definitive one.

Acknowledgements This Project was supported by funding from Fudan Institute for Advanced Studies in Social Sciences. Professor Breslin's research is funded by a Leverhulme Trust Major Research Fellowship (No. MRF-2016-103) on "China Risen: What is Global Power (and in What Ways Does China Have it)?"

\section{Compliance with Ethical Standards}

Conflict of interest On behalf of all authors, the corresponding author states that there is no conflict of interest.

Open Access This article is licensed under a Creative Commons Attribution 4.0 International License, which permits use, sharing, adaptation, distribution and reproduction in any medium or format, as long as you give appropriate credit to the original author(s) and the source, provide a link to the Creative Commons licence, and indicate if changes were made. The images or other third party material in this article are included in the article's Creative Commons licence, unless indicated otherwise in a credit line to the material. If material is not included in the article's Creative Commons licence and your intended use is not permitted by statutory regulation or exceeds the permitted use, you will need to obtain permission directly from the copyright holder. To view a copy of this licence, visit http://creativecommons.org/licenses/by/4.0/.

Shaun Breslin is Professor of Politics and International Studies at the University of Warwick, and CoEditor of The Pacific Review. He currently holds a Leverhulme Major Research Fellowship to study the nature of China as a global power. 